\title{
Effectiveness of Air Filters and Air Cleaners in Allergic Respiratory Diseases: A Review of the Recent Literature
}

\author{
James L. Sublett
}

Published online: 20 July 2011

(C) The Author(s) 2011. This article is published with open access at Springerlink.com

\begin{abstract}
Air filtration is frequently recommended as a component of environmental control measures for patients with allergic respiratory disease. Residential air filtration can be provided by whole house filtration via the home's heating, ventilation, or air conditioning system, by portable room air cleaners, or a combination of the two. Appliances to filter the sleep breathing zone also have been developed. High-efficiency whole house filtration, high-efficiency particulate air sleep zone air filtration, and high-efficiency particulate air room air cleaners all appear to provide various degrees of benefit. Recent studies of various types of filtration, used alone or as part of more comprehensive environmental control measures, are reviewed.
\end{abstract}

Keywords Air cleaner-Air filter-Air filtration - Breathing zone $\cdot$ CADR $\cdot$ Clean air delivery rate $\cdot$ Environmental control · Furnace filter · HEPA · HVAC · Indoor air - Indoor allergens · Intervention measures · Ozone $\cdot$ Particulate matter. PM - Room air cleaner. Sleep breathing zone . Ventilation $\cdot$ Whole house filtration

J. L. Sublett

Department of Pediatrics,

University of Louisville School of Medicine,

Louisville, KY 40223, USA

J. L. Sublett $(\bowtie)$

Family Allergy \& Asthma,

9800 Shelbyville Road, Suite 220,

Louisville, KY 40223, USA

e-mail: jsublett@familyallergy.com

\section{Introduction}

Environmental control practices (ECPs) are a group of measures recommended to reduce exposure to indoor allergens (eg, dust mites, household pets, cockroaches, mold, mice) or nonallergic triggers (eg, environmental tobacco smoke [ETS], wood smoke, volatile organic compounds, particulate matter [PM]) [1]. Historically, many of the common suggestions have been empiric and not based on scientific data or evidence-based clinical trials. As a better understanding of the impact of the characteristics of housing stock $[2,3]$ and occupants [4] on the indoor living environment has evolved, more effective measures have been identified. These may include modification of the occupant's habits, remediation, and/or modification of the dwelling and its furnishings, structure, or ventilation, including the use of air filtration. One major drawback in many ECP studies has been the focus on a single allergen (eg, dust mites [5]) or intervention (eg, room air filtration for cat or dog allergy [6-8]). In fact, most allergic individuals have polysensitivity to multiple allergens. ECPs are therefore much more likely to be beneficial if targeted against triggers or allergens known to be problematic for the individual.

In the case of filtration, little attention has been paid to variations among the various appliances themselves, and no clinical comparisons have been done between the benefits of whole house filtration (WHF) versus those of portable room air cleaners (PRACs). According to the most recent American Housing Survey, $75 \%$ of US housing units have ducted forced air heat, while $63 \%$ have ducted central air conditioning [9]. When used in combination, these ducted heating systems are termed heating, ventilation, air 
conditioning (HVAC) systems. HVAC systems offer the opportunity for WHF, but poorly maintained or contaminated systems may actually increase the risk of asthma and other allergic respiratory symptoms [10]. Simple forgetfulness by the occupants in replacing the filter at suggested maintenance intervals may be the most common issue. HVAC service technicians frequently find filters that have not been changed for years when providing repair or maintenance services [11]. Dirty filters themselves can become a source for air contamination by allergens, particularly fungal spores [12], and can then be trapped, colonized, and released downstream as the overloaded filter fails [13]. Other issues, including air bypass from poor filter fit and duct leakage, may further confound the effectiveness of filtration in HVAC systems.

A barrier to proof of effectiveness for ECPs is the complexity of the gene-host-environment interactions. Expectations have been tainted by the fact that short-term drug studies of only a few weeks' or months' duration can show statistical effectiveness for improvement of symptoms. However, despite major advances in the drugs available for the treatment of allergy and asthma, none have been shown to arrest disease progression permanently. Improved understanding on how to avoid or reduce triggers would be expected to have this benefit. This may not occur in the short term. Observational epidemiology has already led to the recognition of a wide range of triggers found in the indoor environment, ranging from dust mite to diesel exhaust particulates. Applied epidemiologic studies are helpful in understanding targeted avoidance and prevention of disease progression.

Morgan et al. [14], as part of the Inner-City Asthma Study Group, conducted a randomized controlled trial of comprehensive ECPs in 937 children with atopic asthma. All were sensitized, as demonstrated by positive skin test, to at least one indoor allergen. A baseline home evaluation included both direct visual inspections and dust collection from the child's bedroom. Targeted ECPs were then implemented based on skin testing results and the home evaluation. Interventions included the use of a highefficiency particulate air (HEPA) room air cleaner in the child's bedroom if the child was exposed to ETS, sensitized and exposed to cat or dog allergens, or sensitized to mold. The intervention group reported significantly fewer symptoms of asthma during the intervention year and the followup year. The maximal number of days with symptoms was lower in the intervention group by 0.82 day per 2 -week period in the first year $(P<0.001)$ and 0.60 day per 2 -week period in the second year $(P<0.001)$. This effect is similar to that described in placebo-controlled studies of inhaled corticosteroids. The authors concluded that an "individualized, home-based, comprehensive environmental intervention decreases exposure to indoor allergens, and results in reduced asthma-associated morbidity." This study and its outcomes represent the current thought that multiple ECPs, but not single interventions, are effective in modulating symptoms of allergic disease.

A recent review of 3,727 adults with asthma by Roy and Wisnivesky [15], using data from the Four-State National Asthma Survey, examined the association between preventive asthma care and comprehensive ECPs. Comprehensive management was defined as the implementation of combinations of at least five of eight measures. Air filtration was found to be the fourth $(27.4 \%)$ most commonly implemented strategy, preceded only by no smoking $(80 \%)$, no pets $(53.9 \%)$, and washing sheets in hot water $(43.2 \%)$, and followed by pillow covers $(23.7 \%)$, mattress covers (23.4\%), no carpets (14.5\%), and use of a dehumidifier $(13.8 \%)$. A similar study in the pediatric population found the same rate of air filtration (27.4\%) use in the households of asthmatic children [16].

\section{Prior Review Articles on Air Filtration}

The role of air filtration in providing relief for individuals with allergic respiratory illness has been studied for more than 40 years $[17,18]$. Prior reviews of air filtration have focused primarily on PRACs and the effect on patient symptom scores [19-21]. Reisman [19] stated that the studies should focus only on IgE-proven disease and HEPA PRACs. Wood [20] concluded that while HEPA PRACs may be an option for cat and dog allergy, there was no evidence they were effective for dust mite or mold allergy. Focusing only on allergies does not take into consideration the effects of PM and other indoor air pollutants. McDonald et al. [21] reported a meta-analysis of the only 10 randomized controlled trials on filtration published from 1973 through 1999. All 10 trials included asthmatic patients. The authors found a small statistically significant improvement in total symptoms and sleep disturbance associated with use of air cleaners, but no improvement in nasal symptoms, medication use, or peak expiratory flow (PEF) values.

In a 2010 rostrum article, Sublett et al. [22••] provided a comprehensive review of air filtration. The authors described the characteristics of airborne particulates, including allergens, to be filtered, and pointed out that the impact of inhalable PM and the effect on disease is not always $\operatorname{IgE}$ mediated. Residential air-cleaning products and devices are categorized into two broad categories: WHF (ie, filters or cleaners that are installed on the central HVAC system) and free-standing PRACs. Current standards for testing to determine the American Society of Heating, Refrigeration, and Air-Conditioning Engineer's (ASHRAE) minimum efficiency rating value (MERV) for furnace filters and the 
Association of Home Appliance Manufacturers rating system clean air delivery rate (CADR) for room air cleaners are outlined. They also described the results of 18 studies on air filtration from 1973 to 2009, including some studies previously reviewed. The authors concluded that for the "optimal choice of cleaning devices, initial cost and ease of regular maintenance should be considered. PRACs with HEPA filters, especially those that filter the breathing zone during sleep, appear to be beneficial. For the millions of households with forced air HVAC systems, regular maintenance schedules and the use of high-efficiency disposable filters appear to be the best choices." They, as had previous reviewers, recommended that more rigorous study methods be applied to future research on air filtration and that the studies be of sufficient duration to show effectiveness.

Since the Wood [20] and McDonald et al. [21] reviews, there have been 14 studies (Table 1) published that are applicable to the role of air filtration as an environmental control measure for allergic respiratory diseases.

\section{Studies of Whole House Filtration}

Most studies of WHF are engineering modeling studies to determine particulate removal as related to an overall assessment of the ventilation effects in a building. The clinical impact of WHF in allergy or asthma patients has been studied only recently.

Johnson et al. [23•], in a single-blind study of 219 children with asthma from 186 homes, tested the effectiveness of simple low-cost home interventions, including WHF, in improving health scores. On completion of both a health and a home assessment, intervention measures based on predetermined protocols were implemented. Homes were cleaned of visible mold, and repairs were made to eliminate water intrusion. Interventions included the use of a high-efficiency (MERV 12) furnace filter (72.3\%) and HVAC service (78.2\%) for homes identified with (HVAC) problems, such as dirty or contaminated air exchange units or improperly fitted filters. Additional interventions included a room air cleaner (69.3\%) placed in the child's bedroom, basement dehumidifier (54.5\%), and dryer exhaust ventilation (35.6\%). All four interventions were used in $33.7 \%$ of the homes. Asthma quality-of-life surveys indicated improvement after intervention. The most effective interventions relative to symptoms were HVAC servicing with improved air filtration $(P<0.05)$ and dehumidifiers $(P<0.05)$. Room air cleaners were also beneficial, but the study did not indicate which homes had both the HVAC servicing with improved whole filtration plus additional room air cleaners.

Fisk et al. [24] applied a mass-balance model to estimate reductions in the indoor concentrations for a range of particle sizes during use of various air filtration systems, including both HVAC systems and PRACs. They concluded that for cat and dust mite allergen - predominantly found in particles with a diameter of several micrometers-the predicted reductions in indoor mass concentrations (mass per unit air volume) ranged from less than $20 \%$ for the typical inexpensive (fiber glass-woven) furnace filter (no ASHRAE rating) to $60 \%$ for a HEPA filter. Moderate-efficiency filters (MERV 11-12) worked well for the larger diameter particles. Increasing filter efficiencies above ASHRAE 65\% to $85 \%$ (MERV 11-13) to a HEPA filter did not reduce indoor concentrations significantly. For ETS fine-mode particles $\left(<\mathrm{PM}_{2.5}\right), 80 \%$ decreases in indoor concentrations were attainable with filter efficiencies in the same range (MERV 11-13) and flow rates. Increasing the filter efficiency above ASHRAE 85\% (MERV 13) to HEPA resulted in only modest predicted incremental decreases in indoor concentrations of these smaller particles. Filters with an efficiency rating of ASHRAE 45\% (MERV 9) or lower were not found to be effective for reducing indoor concentrations of these smaller particles. In addition, in modeling for the PRACs, they found increasing airflow exchange rates to be more important than increasing filter efficiencies to HEPA. This reflects a point made in the rostrum article [22••] — that the three critical attributes of an air filter are the balance of efficiency, holding capacity of the filter as it loads with dust, and adequate airflow through the filter throughout its expected life. (Fig. 1).

Macintosh et al. [25••] described an experimental model developed to measure the effectiveness of WHF for particle removal. Modeled off the standard CADR, the whole house clean air delivery rate (WHCADR) is calculated based on a methodology that reports airborne particulate removal rates of air-cleaning systems. The testing accounted for the effect of dust settling to surfaces and losses within the HVAC of homes with a central ventilation system. Using a test house modeled after the National Institute for Standards and Technology test home (1,350 square feet, seven rooms and bathroom with eight-foot ceilings), they compared the effectiveness of various types of central HVAC filtration systems and room air cleaners. Air-cleaning systems were challenged with a standard fine dust aerosolized inside the test home. The various air-cleaning units were run for $80 \mathrm{~min}$. Each unit was tested six times. Measures were also made running the HVAC system with no filter to calculate the reduction in particulates by deposition in the ductwork. The WHCADR for each scenario was then calculated in terms of cubic meters per minute. Findings from this study included the following:

1. Running the system with no filter removed approximately one third of 3- to 5- $\mu \mathrm{m}$ aerosols and one half of the 5 - to $10-\mu \mathrm{m}$ aerosols, but less than $10 \%$ of smaller particles. 
Table 1 Filtration studies conducted since 2002

\begin{tabular}{|c|c|c|c|c|}
\hline Study (year) & Filtration type & Study design & Measures & Results \\
\hline $\begin{array}{l}\text { Fisk et al. } \\
\text { [24] (2002) }\end{array}$ & WHF, HEPA PRAC & Modeling & $\begin{array}{l}\text { Particulate } \\
\text { removal }\end{array}$ & $\begin{array}{l}\text { MERV 11-12 HVAC filters } \\
\text { effective for particulate } \\
\text { reduction; ventilation } \\
\text { rates of PRAC important }\end{array}$ \\
\hline $\begin{array}{l}\text { Francis et al. } \\
\text { [28] (2003) }\end{array}$ & HEPA PRAC & $\begin{array}{l}\text { In home, randomized, } \\
\text { parallel }\end{array}$ & $\begin{array}{l}\text { Asthma } \\
\text { outcomes }\end{array}$ & $\begin{array}{l}\text { Decreased bronchial reactivity; } \\
\text { no change in lung function }\end{array}$ \\
\hline $\begin{array}{l}\text { Gore et al. } \\
\text { [29] (2003) }\end{array}$ & HEPA PRAC & $\begin{array}{l}\text { In home, airborne, } \\
\text { allergen assay }\end{array}$ & $\begin{array}{l}\text { Personal } \\
\text { allergen }\end{array}$ & $\begin{array}{l}\text { PRACs reduced exposure in } \\
\text { rooms while cat was present }\end{array}$ \\
\hline $\begin{array}{l}\text { Morgan et al. } \\
\text { [14] (2004) }\end{array}$ & $\begin{array}{l}\text { HEPA PRAC as } \\
\text { part of ECP }\end{array}$ & $\begin{array}{l}\text { In home, randomized } \\
\text { controlled }\end{array}$ & $\begin{array}{l}\text { exposure } \\
\text { Asthma } \\
\text { outcomes }\end{array}$ & $\begin{array}{l}\text { Symptom scores improved } \\
\text { in ECP group }\end{array}$ \\
\hline $\begin{array}{l}\text { Batterman et al. } \\
\text { [30] (2005) }\end{array}$ & HEPA PRAC & $\begin{array}{l}\text { In-home particulate } \\
\text { measurement }\end{array}$ & $\begin{array}{c}\text { Particulate } \\
\text { removal }\end{array}$ & $\begin{array}{l}\text { PRACs reduced exposure } \\
\text { to PM }\end{array}$ \\
\hline $\begin{array}{l}\text { Bernstein et al. } \\
\text { [31] (2005) }\end{array}$ & $\begin{array}{l}\text { HEPA PRAC with } \\
\text { dehumidifier }\end{array}$ & $\begin{array}{l}\text { Day care facility mold } \\
\text { levels }\end{array}$ & $\begin{array}{l}\text { Culturable } \\
\text { mold } \\
\text { levels }\end{array}$ & Mold levels decreased \\
\hline $\begin{array}{l}\text { Hacker and Sparrow } \\
\text { [33] (2005) }\end{array}$ & $\begin{array}{l}\text { HEPA PRAC, electrostatic } \\
\text { ionizer, SBZ HEPA }\end{array}$ & $\begin{array}{l}\text { Model room } \\
\text { particulate counts }\end{array}$ & $\begin{array}{l}\text { Measured room } \\
\text { and SBZ } \\
\text { particle } \\
\text { counts }\end{array}$ & $\begin{array}{l}\text { HEPA CADR reduced room } \\
\text { particle counts; } \\
\text { SBZ HEPA best for SBZ; } \\
\text { ionizers had poor } \\
\text { performance }\end{array}$ \\
\hline $\begin{array}{l}\text { Morris et al. } \\
\text { [34] (2006) }\end{array}$ & SBZ HEPA & In home, crossover & $\begin{array}{l}\text { Seasonal } \\
\text { allergic } \\
\text { rhinitis outcomes }\end{array}$ & $\begin{array}{l}\text { Reduction in morning and } \\
\text { evening symptom scores }\end{array}$ \\
\hline $\begin{array}{l}\text { Macintosh et al. } \\
{[25 \bullet \bullet](2008)}\end{array}$ & $\begin{array}{l}\text { WHF, HEPA PRAC, } \\
\text { ionizer }\end{array}$ & Modeling & $\begin{array}{l}\text { Particulate } \\
\text { removal }\end{array}$ & $\begin{array}{l}\text { WHF performed best; } \\
\text { PRAC effective in } \\
\text { rooms where } \\
\text { used; ionizer } \\
\text { ineffective }\end{array}$ \\
\hline $\begin{array}{l}\text { Myatt et al. } \\
\text { [27] (2008) }\end{array}$ & $\begin{array}{l}\text { WHF, HEPA PRAC, } \\
\text { ionizer }\end{array}$ & Modeling & $\begin{array}{l}\text { Particulate } \\
\text { removal }\end{array}$ & $\begin{array}{l}\text { WHF performed best; } \\
\text { PRAC effective in } \\
\text { rooms where used; } \\
\text { ionizer ineffective }\end{array}$ \\
\hline $\begin{array}{l}\text { Sulser et al. } \\
\text { [32] }(2009, \text { study } \\
\text { conducted in 2000) }\end{array}$ & HEPA PRAC & $\begin{array}{l}\text { In home, randomized } \\
\text { controlled, pet allergy } \\
\text { only }\end{array}$ & Asthma outcomes & $\begin{array}{l}\text { Reduction in nocturnal } \\
\text { symptoms }\end{array}$ \\
\hline Johnson et al. [23•] (2009) & WHF/PRAC as part of ECP & Single blind & Asthma outcomes & $\begin{array}{l}\text { HVAC service with WHF } \\
\text { improved symptoms scores }\end{array}$ \\
\hline Pedroletti et al. [35] (2009) & SBZ HEPA & $\begin{array}{l}\text { In home, randomized, } \\
\text { double-blind, placebo } \\
\text { controlled, crossover }\end{array}$ & Asthma outcomes & $\begin{array}{l}\text { Symptom scores and } \\
\text { quality-of-life } \\
\text { measures improved; } \\
\text { eNO improved; } \\
\text { no change in lung } \\
\text { function }\end{array}$ \\
\hline Stillerman et al. [36•] (2010) & $\begin{array}{l}\text { SBZ HEPA with } \\
\text { mite-proof pillow } \\
\text { encasing }\end{array}$ & $\begin{array}{l}\text { In home, randomized, } \\
\text { double-blind, placebo } \\
\text { controlled, crossover }\end{array}$ & $\begin{array}{l}\text { Perennial allergic } \\
\text { rhinitis outcomes; } \\
\text { SBZ particle } \\
\text { counts }\end{array}$ & $\begin{array}{l}\text { SBZ particle counts reduced; } \\
\text { significant improvement in } \\
\text { waking and overnight } \\
\text { reflective symptom scores; } \\
\text { improved quality-of-life } \\
\text { measures }\end{array}$ \\
\hline
\end{tabular}

$C A D R$ clean air delivery rate; $E C P$ environmental control practice; $e N O$ exhaled nitrous oxide; HEPA high-efficiency particulate air; $H V A C$ heating, ventilation, air conditioning; $M E R V$ minimum efficiency rating value; $P M$ particulate matter; $P R A C$ portable room air cleaner; $S B Z$ sleep breathing zone; $W H F$ whole house filtration

2. Running the central system with a 1-in MERV 2 furnace filter or the ionic portable air cleaner (running in three rooms simultaneously) yielded no better results than having no filter. 


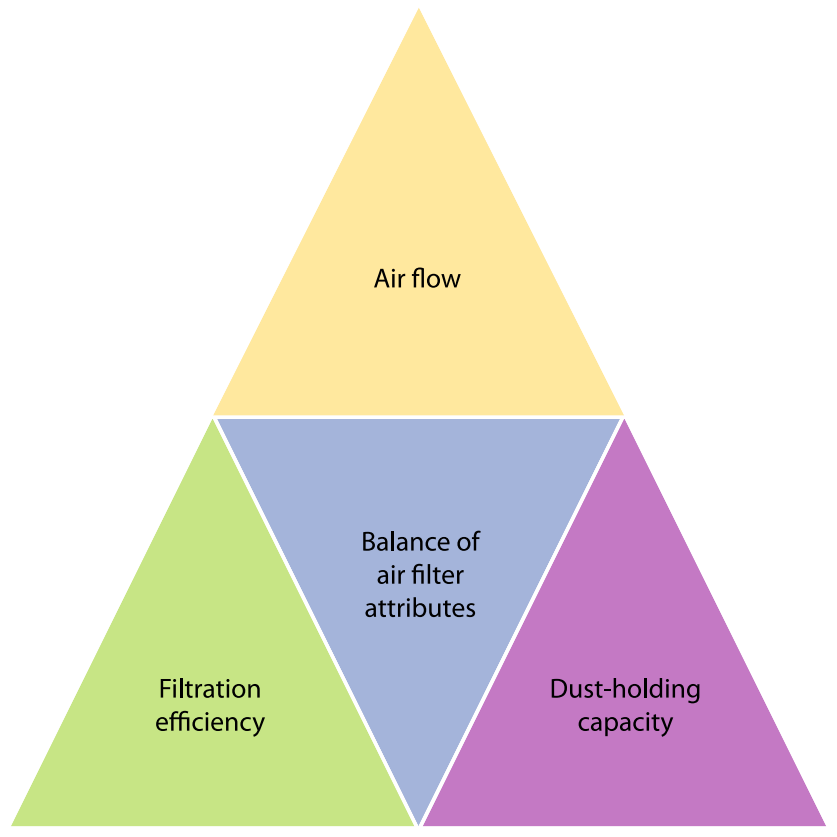

Fig 1 Balance: the key to the attributes of any air filter. That balance is as follows: 1) air flow to assure adequate ventilation, 2) efficiency to filter out a range of small particle sizes, and 3 ) capacity to allow for reasonable cost-effective maintenance schedules without adversely affecting airflow and efficiency

3. Operation of the three ionic air cleaners yielded an increase in submicrometer particles during tests. This may be due to the interaction of volatile organic compounds and the ozone produced by the ionizers.

4. Running a single HEPA PRAC in one room did not provide air cleaning in other rooms in the house.

5. Air cleaning can be achieved as long as the WHCADR is greater than the whole house air exchange rate (mean residential air exchange rate in the United States is 0.71 air changes per hour [26]). All three of the studied higher efficiency HVAC WHF air filters/cleaners achieved this, as did running HEPA PRAC in five rooms simultaneously.

6. Five HEPA units running in separate rooms in the house had a WHCADR of only $58 \%$ of the theoretical CADR of the individual units. This may be due to the inability of the room units to draw air from other spaces outside the room in which they were positioned.

The same investigators, in a study by Myatt et al. [27], applied a multizone indoor air quality model developed by the National Institute of Standards and Technology to estimate indoor concentrations of indoor triggers associated with asthma. Using two test houses representing typical one-story and two-story detached homes $(>60 \%$ of US housing stock), they modeled five different ventilation and filtration configurations:

1. 1-in MERV 2 HVAC filter.
2. 5-in media MERV 8 HVAC filter.

3. 1-in MERV 2 HVAC filter with one HEPA PRAC in a bedroom.

4. 1-in MERV 2 HVAC filter with HEPA PRAC in the bedroom and living/family room.

5. A high-efficiency electrostatic air cleaner installed on the HVAC system.

The MERV 8 furnace filter and the air cleaner performed better unless the HEPA room air cleaner was used in the same room as the source (eg, running it in the room with cat exposure). The investigators concluded that although the use of a portable air cleaner will "provide exposure benefits in the room it is located, concentrations of common asthma triggers throughout the residence, and corresponding personal exposures, are not likely to be mitigated" and that the "modeling analysis indicate that high efficiency in-duct air cleaning systems would yield a more substantial reduction in personal exposure than the portable air cleaners used in intervention studies published to date."

\section{Studies of Portable Room and Sleep Breathing Zone Air Cleaners}

Room air cleaners offer portability and provide filtration in homes without forced air HVAC systems. They are offered in a variety of sizes, and the filtration types generally fall into two categories: HEPA filters and electronic electrostatic devices.

In a year-long, randomized, parallel-group study, Francis et al. [28] measured the clinical outcomes for the use of HEPA air cleaners in both the bedroom and living room of 30 adult asthmatics who were both sensitized to and lived with (against medical advice) an indoor cat or dog. The control group and the active group also used cyclonic HEPA vacuums twice per week. Primary end points in combined asthma outcomes (bronchial reactivity and treatment requirements) were statistically improved in the treatment group over the controls. Secondary end points of lung function and allergen levels improved in both groups and were not statistically significant.

Gore et al. [29] measured the amount of cat allergen found on nasal personal air samplers using HEPA PRACs in five homes with indoor cats over 4 separate days. They found significant reductions in the amount of measured Fel $\mathrm{d} 1$ when the PRAC was used with the cat in the room $(P<0.01)$ but no difference $3 \mathrm{~h}$ after the cat was removed from the room. The study was limited by the small number of homes studied, the short duration of use of the PRACs, and the fact that the mean ventilation rate of the PRACs used was only $4.09 \mathrm{~m}^{3 /} \mathrm{h}$ (range, $8.9-2.8 \mathrm{~m}^{3} / \mathrm{h}$ ). It did demonstrate that even 
small allergens such as cat will fall out into settled dust within a few hours and will not be affected by air filtration. Because settled dust is stirred and becomes airborne during the times people and pets are active in the household, this study does support air filtration as a means of reducing exposures.

An excellent overall discussion of air filtration is provided by Batterman et al. [30] in reporting the results of a 2-month study of the effects of continuous use of HEPA PRACs in the homes of cigarette smokers. The PRAC decreased PM concentrations by $30 \%$ to $70 \%$, depending on size fraction and occupant activities. They concluded that PRACs can reduce exposure of PM that has been associated with the exacerbation of asthma and other respiratory symptoms, but that further research is necessary to determine whether such filters improve respiratory health.

Bernstein et al. [31] reported the first study to investigate the effect of dehumidification in conjunction with HEPA filtration as an intervention to control airborne culturable mold levels. They were able to show reduction in airborne mold levels, but it was not possible in this study to determine whether the reduction of airborne mold spore levels was due mainly to dehumidification or air filtration intervention.

A recently published study by Sulser et al. [32] of children sensitized to cat or dog compared sham versus HEPA PRACs placed in the living room and bedroom. The research, conducted in 1999 and 2000, excluded children also sensitized to dust mite or known mold exposure. A significant reduction in nocturnal symptoms was observed, as was a trend in the active group toward an improvement in bronchial hyperresponsiveness.

A standard test bedroom was devised by Hacker and Sparrow [33] for the evaluation of six commercially available air cleaners. The brands of the units were not identified, but photos of the units were provided. Three were electrostatic precipitators, and three used HEPA filtration. Two of the HEPAs were PRACs, and one a stationary model designed for use at the headboard end of a bed to provide filtration to the "sleep breathing zone" (SBZ). One of the electrostatic units was a tower unit with no fan. Particulate counts were taken at 1-min intervals over an 8-h period at the approximate position of the SBZ. To measure device performance, they reported three components of the appliances effectiveness: 1) the time-wise variation of particulate concentration measured in the experimental breathing zone of a sleeping person, 2) average particle size concentration over the 8-h test period, and 3) efficiency of particle removal as measured over the inflow/outflow of the units. Reduction of particle concentration ranged from nearly complete removal of all particles by the SBZ unit to no benefit over natural particle-settling rates by the tower unit with no fan. (This unit appears to be a well-known national brand highly promoted by infomercials that was also found ineffective in the studies by Macintosh et al. [25••].) The electrostatic devices did not perform as well as a group. There was no assessment of the amount of ozone these machines may generate. All three HEPA appliances had excellent efficiency measures. The SBZ unit provided the best overall performance because of its special design to clean the breathing zone.

The concept of focusing on creating a particle-free SBZ dates back to the previously mentioned study by Zwemer and Karibo [18], which looked at a filtration system built into a headboard of a bed. Three studies, one by Morris et al. [34] and more recent ones by Pedroletti et al. [35] and Stillerman et al. [36•], looked at various HEPA SBZ filtration systems. Morris et al. [34] studied the use of a laminar flow HEPA unit that could be positioned over the SBZ. They studied 14 ragweedsensitive individuals with allergic rhinitis during the ragweed season. The duration of filter use was 3 weeks. Outcome measures included recording morning and evening symptom scores, the Juniper Rhinitis Quality of Life Questionnaire, and the Epworth Sleepiness Scale, along with tolerability rating. The total group showed an average of $26 \%$ reduction in morning symptoms ( $P=0.025$ compared with baseline) and an average of $24 \%$ reduction in evening symptoms $(P=0.013)$.

Pedroletti et al. [35] studied 22 patients 12 to 33 years of age with mild to moderate asthma in a 10 -week, doubleblind, placebo-controlled, crossover trial. All were sensitized to cat or $\operatorname{dog}$, and $76.2 \%$ were also sensitized to dust mite, birch tree pollen, or both. The device tested provided laminar airflow of cooled, HEPA-filtered air directed to the SBZ. It is designed so that a "shower" of cooled, filtered air displaces air containing particles, including allergens, in the SBZ. The primary effectiveness measure was the change in quality of life between active versus placebo treatment, assessed by the mini-Asthma Quality of Life Questionnaire. In addition, changes in exhaled nitrous oxide and spirometry were assessed. At the end of the 10 weeks, the treatment group showed improvement in both the mini-Asthma Quality of Life Questionnaire $(P<0.05)$ and exhaled nitrous oxide $(P<$ $0.05)$. Both effects occurred within the first 2 and 5 weeks, respectively, of treatment. There were no significant changes in pulmonary functions from baseline.

Stillerman et al. [36•] studied a combination of a HEPA filtration attached to a dust mite-proof pillow encasement. This unique configuration also was designed to provide a particle-free SBZ. They studied 35 patients with perennial allergic rhinoconjunctivitis ( $75 \%$ moderate to severe) in a randomized, double-blind, placebo-controlled, crossover trial lasting 42 weeks. Patients were assessed by skin prick testing. A total of $89 \%$ were dust mite sensitive, $57 \%$ cat 
sensitive, and $47 \%$ were sensitized to dog. Allergen levels from vacuum dust sampling in the bedroom and bedding were also measured. Only $43 \%$ percent of the patients had significant exposures to at least one of the sensitizing allergens. (This would imply that symptoms might be due to other allergens not tested [eg, mold], or from a nonallergic trigger, including particulates.) Allergy medications were prohibited. Instantaneous and reflective Total Nasal Symptom Scores (TNSS) were recorded daily. Quality-of-life scores were recorded weekly using the Nocturnal Rhinoconjunctivitis Quality of Life Questionnaire. Particle counts showed that active and placebo devices reduced SBZ particles measuring at least $0.3 \mu \mathrm{m}$ from a median background level of 712,680/ cubic foot to median levels of $80 /$ and 548,050/cubic foot, respectively. The active treatment group had significant improvement versus placebo $(P<0.001)$ in both instantaneous on waking and overnight reflective TNSS. Daytime TNSS did not improve. Nocturnal Rhinoconjunctivitis Quality of Life Questionnaire scores were also significantly better in the active treatment group, especially in patients with moderate to severe symptoms.

\section{Conclusions}

Air filtration is frequently recommended as a component of environmental control practices for patients with allergic respiratory disease. Studies support multiple interventions, including air filtration, as methods to improve outcomes in the treatment of allergic respiratory diseases. Residential air filtration can be provided by WHF via the home's HVAC system, PRACs, or a combination of both. Appliances to filter the SBZ also have been developed. HVAC systems may create a reservoir for triggers if they are not wellmaintained. Inexpensive, low-efficiency HVAC filters offer no better particle removal than no filter. WHF with highefficiency HVAC filtration is shown to be more effective in particulate reduction than individual HEPA PRACs. One study combining HVAC maintenance with a disposable high-efficiency MERV 12 HVAC filter has shown clinical benefit of WHF in asthma. A study of HEPA PRACs trended toward clinical benefit, but their effectiveness is limited to a single room and not the entire dwelling. Several - placed in various rooms - are needed to approach the benefit of high-efficiency WHF. Ionic electrostatic room air cleaners provide little or no benefit compared with WHF or HEPA PRACs. Ionic appliances produce ozone, a respiratory irritant, and in one study caused an increase in submicrometer particulates. SBZ filtration was shown to be effective in three clinical studies. The best and most cost-effective approach may be to consider "combination filtration" using high-efficiency WHF with PRAC or breathing zone filtration in the bedroom.
Disclosure Dr. Sublett has received honoraria and received payment for development of educational presentations (including service on speakers' bureaus) from GlaxoSmithKline, ISTA Pharmaceuticals, Merck \& Co., and Teva Respiratory, and has held stock in AllergyZone.

Open Access This article is distributed under the terms of the Creative Commons Attribution Noncommercial License which permits any noncommercial use, distribution, and reproduction in any medium, provided the original author(s) and source are credited.

\section{References}

Papers of particular interest, published recently, have been highlighted as:

- Of importance

-• Of major importance

1. Eggleston PA. Improving indoor environments: reducing allergen exposures. J Allergy Clin Immunol. 2005;116(1):122-6.

2. Small BM. Creating healthier buildings. Toxicol Ind Health. 2009;25(9-10):731-5.

3. Jacobs DE, Kelly T, Sobolewski J. Linking public health, housing, and indoor environmental policy: successes and challenges at local and federal agencies in the United States. Environ Health Perspect. 2007;115(6):976-82.

4. Chen Q, Hildemann LM. The effects of human activities on exposure to particulate matter and bioaerosols in residential homes. Environ Sci Technol. 2009;43(13):4641-6.

5. Sheikh A. et al. House dust mite avoidance measures for perennial allergic rhinitis. Cochrane Database of Systematic Reviews. 2010; (7):CD001563.

6. Green $\mathrm{R}$ et al. The effect of air filtration on airborne dog allergen. Allergy. 1999;54(5):484-8.

7. Custovic A et al. Distribution, aerodynamic characteristics, and removal of the major cat allergen Fel $\mathrm{d} 1$ in British homes. Thorax. 1998;53(1):33-8.

8. Wood RA et al. A placebo-controlled trial of a HEPA air cleaner in the treatment of cat allergy. Am J Respir Crit Care Med. 1998;158 (1):115-20.

9. American Housing Survey for the United States: 2009, 2011, U.S. Census Bureau.

10. Zock JP et al. Housing characteristics, reported mold exposure, and asthma in the European Community Respiratory Health Survey. J Allergy Clin Immunol. 2002;110(2):285-92.

11. ASHRAE, Building Maintenance Linked to Indoor Air Quality Problems. ASHRAE Journal, 1996(April).

12. Simmons RB, Crow SA. Fungal colonization of air filters for use in heating, ventilating, and air conditioning (HVAC) systems. J Ind Microbiol. 1995;14(1):41-5.

13. Hanssen SO. HVAC - the importance of clean intake section and dry air filter in cold climate. Indoor Air. 2004;14 Suppl 7:195-201.

14. Morgan WJ et al. Results of a home-based environmental intervention among urban children with asthma. N Engl J Med. 2004;351(11):1068-80.

15. Roy A, Wisnivesky JP. Comprehensive use of environmental control practices among adults with asthma. Allergy Asthma Proc. 2010;31(5):72-7.

16. Roy A, Downes MJ, Wisnivesky JP. Comprehensive environmental management of asthma and pediatric preventive care. Pediatr Allergy Immunol. 2011;22(3):277-82. 
17. Barach AL. A room filter for the removal of dust, pollen and air pollutants: preliminary report. Ann Allergy. 1969;27(10):519-20.

18. Zwemer RJ, Karibo J. Use of laminar control device as adjunct to standard environmental control measures in symptomatic asthmatic children. Ann Allergy. 1973;31(6):284-90.

19. Reisman RE. Do air cleaners make a difference in treating allergic disease in homes? Ann Allergy Asthma Immunol. 2001;87(6 Suppl 3):41-3.

20. Wood RA. Air filtration devices in the control of indoor allergens. Curr Allergy Asthma Rep. 2002;2(5):397-400.

21. McDonald E et al. Effect of air filtration systems on asthma: a systematic review of randomized trials. Chest. 2002;122(5):153542.

22. • Sublett J.L., et al. Air filters and air cleaners: rostrum by the American Academy of Allergy, Asthma \& Immunology Indoor Allergen Committee. J Allergy Clin Immunol. 2010;125(1):32-8. This is a comprehensive review of residential air filtration, various types of filtration available, characterization of airborne particulates, and standards for rating both HVAC and room air cleaners. It also provides recommendations related to future research.

23. - Johnson L., et al. Low-cost interventions improve indoor air quality and children's health. Allergy Asthma Proc. 2009;30 (4):377-85. This was the first clinical study of asthma using environmental control practice that includes WHF

24. Fisk WJ et al. Performance and costs of particle air filtration technologies. Indoor Air. 2002;12(4):223-34.

25. •- Macintosh D.L. et al. Whole house particle removal and clean air delivery rates for in-duct and portable ventilation systems. J Air Waste Manage Assoc. 2008;58(11):1474-82. This is an introduction of a new standard that allows comparison of various filtration systems in a multiroom test house.

26. Yamamoto $\mathrm{N}$ et al. Residential air exchange rates in three major US metropolitan areas: results from the Relationship Among
Indoor, Outdoor, and Personal Air Study 1999-2001. Indoor Air. 2010;20(1):85-90.

27. Myatt TA et al. Control of asthma triggers in indoor air with air cleaners: a modeling analysis. Environ Health. 2008;7:43.

28. Francis $\mathrm{H}$ et al. Clinical effects of air filters in homes of asthmatic adults sensitized and exposed to pet allergens. Clin Exp Allergy. 2003;33(1):101-5.

29. Gore RB et al. Air filtration units in homes with cats: can they reduce personal exposure to cat allergen? Clin Exp Allergy. 2003;33(6):765-9.

30. Batterman S, Godwin C, Jia C. Long duration tests of room air filters in cigarette smokers' homes. Environ Sci Technol. 2005;39 (18):7260-8.

31. Bernstein JA et al. A pilot study to investigate the effects of combined dehumidification and HEPA filtration on dew point and airborne mold spore counts in day care centers. Indoor Air. 2005;15(6):402-7.

32. Sulser C et al. Can the use of HEPA cleaners in homes of asthmatic children and adolescents sensitized to cat and dog allergens decrease bronchial hyperresponsiveness and allergen contents in solid dust? Int Arch Allergy Immunol. 2009;148 (1):23-30.

33. Hacker DW, Sparrow EM. Use of air-cleaning devices to create airborne particle-free spaces intended to alleviate allergic rhinitis and asthma during sleep. Indoor Air. 2005;15(6):420-31.

34. Morris RJ et al. A novel air filtration delivery system improves seasonal allergic rhinitis. Allergy Asthma Proc. 2006;27(1):63-7.

35. Pedroletti $\mathrm{C}$ et al. Clinical effects of purified air administered to the breathing zone in allergic asthma: a double-blind randomized cross-over trial. Respir Med. 2009;103(9):1313-9.

36. - Stillerman A. et al. Efficacy of a novel air filtration pillow for avoidance of perennial allergens in symptomatic adults. Ann Allergy Asthma Immunol. 2010;104(5):440-9. This was a welldesigned study using validated clinical outcomes. 